\title{
Investigating thermophysiological comfort properties of polyester knitted fabrics
}

\begin{abstract}
Sport clothes are mainly produced from polyester yarn because of good wicking behaviour and moisture transfer properties of this yarn. In this paper, thermophysiological comfort properties of ring staple polyester, textured polyester and special type of polyester knitted fabrics, which is described as good moisture management property yarn by producer, were investigated. For this reason, thermal resistance, thermal absorptivity, thermal conductivity, air permeability and moisture managent properties of fabrics were tested. The results showed that, textured polyester yarn knitted fabrics were showed the highest air permeability values than moisture management polyester in same yarn count and knit structure. Lower filament number fabrics shows higher thermal resistance values in same yarn count of fabrics. Moisture management polyester knitted fabric (Type 10) showed the highest top absorption and one way transport index value. Also moisture management polyester yarn knitted fabrics, except Type 7, were showed very good moisture management properties according to MMT grading scale. This is most probably cross-sectional shape of this fiber.
\end{abstract}

Keywords: thermo physiological comfort, thermal resistance, thermal absorbtivity, moisture management, thermal conductivity

\section{Introduction}

Sport clothes getting more interest from the consumers and production of sportswear in total market is risen to $\% 25$. The basic and universal need of consumers in sport clothing is comfort especially. Because during high activity levels sporters needs to throw away excess heat from the body with sweating. It is only possible with selection of comfortable clothes. Sport clothes are mainly produced from Polyester knitted fabrics. Comfort is a complex issue and defined by some researchers ' absence of unpleasantness or discomfort ' and ' a state of pleasant psychological, physiological and physical harmony'. ${ }^{1,2}$

Thermal comfort of clothes are depends on thermal resistance, water vapor resistance, moisture management and air permeability properties of fabrics. So many researchers have studied about this properties.

Oğlakçıŏlu and Marmaralı ${ }^{3}$ investigated the thermal properties of cotton and polyester based single jersey of $1 \times 1$ rib and interlock structures. The results showed that, Interlock and $1 \times 1$ rib fabrics have a remarkably high thermal conductivity and thermal resistance value. On the other hand, single jersey fabrics have higher relative water vapour permeability values than $1 \times 1$ rib and interlock fabrics, and give a warmer feeling with lower thermal absorptivity values.

Özçelik et al. ${ }^{4}$ investigated comparative thermo-physiological properties of interlock knitted fabrics produced with air-jet textured, false-twist textured and non-textured filament PES yarns, by using the Alambeta instrument. They founded that the thermal resistance of the textured fabrics are higer than the fabrics produced with non-textured filaments.

Fan and Tsang 5 were investigated effect of clothing thermal properties on the comfort sensations of wearers during sport activities. Thermal manikin Walter were used in the experiments for measurements of thermal insulation, moisture vapor resistance and moisture accumulation within clothing of five tracksuits. It was found that the thermal comfort sensations during active sports were strongly
Volume 5 Issue I - 2019

\author{
Esra Taștan Özkan,' Binnaz Meriç \\ Kaplangiray ${ }^{2}$ \\ 'Department of Textile Engineering, University of Bitlis Eren, \\ Turkey \\ ${ }^{2}$ Department of Textile Engineering, University of Uludag, Turkey
}

Correspondence: Esra Taștan Özkan, Department of Textile Engineering, University of Bitlis Eren, Bitlis, Turkey, Tel +905343210708, Email etastan@beu.edu.tr

Received: February 17, 2019 | Published: February 22, 2019 related to the moisture vapor resistance and moisture accumulation within clothing. The overall comfort of sportswear during sports activities was especially related to the moisture related comfort sensations and clothing properties.

Tyagi et al. ${ }^{6}$ investigated diferent experimental conditions on the thermal comfort behaviour of the polyester- viscose and polyestercotton ring and MJS fabric. The results showed that the yarn structure and the fibre cross-sectional shape have a large influence on improving thermal comfort of woven fabrics.

Majumdar et al. ${ }^{7}$ presented thermal properties of different knitted fabric structures made from cotton, regenerated bamboo and cottonbamboo blended yarns. They founded that the thermal conductivity of knitted fabrics generally reduces as the proportion of bamboo fibre increases.

Sampath et al. ${ }^{8}$ investigated effect of moisture management finish on different filament number single jersey polyester knitted fabrics. it was observed that the fabric containing 108 filaments in yarn gives better wetting, higher wicking, and optimum moisture vapor transmission. A new test method was introduced to find out the transverse wicking behavior of the fabrics.

Cubric et al. ${ }^{9}$ investigated significant fabric parameters affecting the heat transfer through a porous structure. For this reason a series of single jersey fabrics samples was knitted and treated according to the same recipe. Results showed that thermal resistance of the knitted fabric, one can observe a strong correlation between the thermal resistance of the knitted fabric and thickness, mass per unit area, cover factor and porosity.

Demiryürek and Uysaltürk ${ }^{10}$ investigated the thermal conductivity, thermal diffusivity, thermal absorptivity, thermal resistance, moisture and air permeability, of Viloft/cotton and Viloft/polyester blended knitted fabrics. They found that the air permeability of $1 \mathrm{x} 1 \mathrm{rib}$ fabrics was lower than that of single-jersey fabrics, which is related to the higher fabric thickness, lower porosity and higher weight values of 1x1 rib fabrics compared to single-jersey fabrics. 
Wang et al. ${ }^{11}$ were investigated evaporative cooling efficiency of one layer tight-fitting sportswear. For this reason Coolmax ${ }^{\circledR}$, merino wool, sports wool and cotton knitted fabrics were selected for the study. The results demonstrated that, for the sportswear materials tested, the real evaporative cooling efficiency linearly decreases with the increasing ratio of moisture being transported away from skin surface to clothing layer. In addition, clothing fabric thickness has a negative effect on the real evaporative cooling efficiency. Clothing $\mathrm{CM}$ and SW showed a good ability in maintaining evaporative cooling efficiency.

Özgen and Altaş ${ }^{12}$ investigated thermal comfort, moisture management and handle properties of fabrics produced $90 \%$ Cotton / $10 \%$ Seacell, 90\% Cotton / 10\% Silver, 100\% Cotton, 100\% Bamboo and $100 \%$ Soybean yarns. They concluded that Soybean fabric gave the best thermal comfort and moisture management properties.

$\mathrm{Lu}$ et al. ${ }^{13}$ were investigated local thermal insulation values of seventeen clothing ensembles of different layers with different air velocities and walking speeds on a thermal manikin 'Newton'. The empirical equations for estimating local resultant clothing insulation as a function of local insulation, air velocity, and walking speed were developed.

Ho et al. ${ }^{14}$ were developed a t-shirt designed with larger air gaps on the shoulders. In order to test the effectiveness of this design method on heat and moisture transfer, a series of testing were conducted by using a movable thermal manikin in a controlled chamber in windy and no wind conditions.

Atasagun et al. ${ }^{15}$ were investigated advantages of Viloft blends used for sportswear, taking into account objective measurements and subjective wear trials. In the study, $1 \times 1$ rib-knitted fabrics were produced from 20 tex yarn made by blending Viloft fiber and natural synthetic, or functional fibers. $100 \%$ cotton, $100 \%$ viscose, and $100 \%$ Coolmax, the most preferred fabrics for sportswear were produced as well. The results showed that mechanical properties of Viloft-blended fabrics have not been superior than commercial fabrics. Viloft/wool fabrics showing high thermal resistance and water vapor resistance have had poor transfer properties. Viloft/Coolmax fabrics with low water vapor resistance and high moisture management properties have come to the forefront in terms of liquid moisture comfort among Viloft-blended fabrics.

Özkan and Meriç ${ }^{16}$ were investigated the thermal and moisture management properties of six different types of polyester knitted fabrics that are used in the production of summer cycling clothes. They were found that warp knitted raschel fabric was more convenient for summer cycling clothing because of its good air permeability, low thermal resistance, low water vaporresistance and good moisture management properties.

Öner and Okur ${ }^{17}$ investigated nvestigated the transfer properties of knitted fabrics which had $1 \times 1$ rib-knitted structure and which were systematically produced from 20 tex yarns made of natural, regenerated cellulosic, synthetic, and functional fibers. The results showed that lyester and cotton/Coolmax fabrics with float structure have good liquid moisture transfer properties and high capillary absorption characteristics. For high-physical activity in hot weather, these fabrics will be advantageous in removing liquid sweat from the body.

This study aimed to investigate thermophysiological comfort properties of three different type of polyester yarn (ring staple polyester, textured polyester and special type of polyester) knitted fabrics. Which are produced from different yarn counts and three types of knitting structure. There are a lot of survey in the literature about thermal properties of polyester knitted fabris. But this research different from the other studies, because moisture management desribed yarn is a special type of polyester which is produced in Turkey which is desribed as good moisture management property yarn by producer. According to test results, some evaluations have been made about fabrics such as thermal resistance, thermal absorptivity, air permeabilily and moisture management.

\section{Material and methods}

The properties of fabrics measured by standart methods are given in Table 1. Also microspope photos of used fibers in the experiments were given in Table 2. Before the fabrics were used in the test, they were placed in a controlled room for 24 hours for conditioning. Air permeability measurements were made SDL Atlas Air permeability instrument according to EN ISO 9237 standarts with $100 \mathrm{~Pa}$ air pressure and $20 \mathrm{~mm}^{2}$ test area. ${ }^{18}$ A moisture management instrument (MMT) was used to measure the dynamic liquid transport properties of knitted samples. The moisture management properties were evaluated using a moisture management tester according to AATCC 195-2009. ${ }^{19}$ Thermal resistance, conductivity and absorptivity measurements were made with Alambeta test device. In this instrument the fabric is kept between the hot and cold plates. The hot plate comes in contact with the fabric sample at a pressure of $200 \mathrm{~Pa}$. As soon as the hot plate touches the fabric surface, the amount of heat flow from the hot surface to the cold surface through the fabric is detected by heat flux sensors. There is also a sensor, which measures the thickness of the fabric. These values are then used to calculate the thermal resistance of fabric.

Single factor variance (ANOVA) analyses were used to determine the statistical significance of the variations. The fabrics used in the experiment were not produced in a controlled chamber. To deduce whether the parameters were significant or not, the $p$ values were examined. If the $p$ value of a parameter was greater than $0.05(p>0.05)$, the parameter was not investigated further.

\section{Results and discussion}

\section{Air permeability}

Air permeability values of fabrics used in the experiments were compared in Figure 1. The lowest air permeability value was seen in the the highest course setting, Type 2-100/108 D Textured Polyester elastan knitted fabric. Type 3 which has lower filamet number and elastan yarn composition was showed higher air permeability value. The highest air permeability value was seen in Type 9, 150/288 Textured Polyester fabric which has one of the lowest thickness value. Second highest air permeability value was seen in Type 1 -30/1 Ring Staple Fiber Polyester knitted single jersey fabric. When we compare Type 8 , Type 9 and Type 10 polyester single jersey knitted fabrics; moisture management polyester knitted fabric was showed lowest air permeability value. Similarly, when we compare Type 5, Type 6 and Type 7, moisture management polyester knitted Type 7 fabric was showed the lowest air permeability value. This is most probably due to textured polyester yarn more voluminous than moisture management polyester yarn. If we compare same yarn count and filament number, Type 4 and Type 7 moisture management polyester knitted fabrics, because of the porous structure mesh knitted fabric (Type 7) was showed the higher air permeability value. Anova 
result of air permeability values was given in Table 3 . The ANOVA results showed that the differences for the different types of fabric construction were significant in terms of the air permeability.

\section{Thermal comfort properties of fabrics}

Thermal conductivity: Thermal conductivity values of fabrics measured with Alambeta test device were given in Figure 2. Thermal conductivity is an intrinsic property of material that indicates its ability to conduct the heat. It is the flux of heat (energy per unit area per unit time) divided by the temperature gradient. Thermal conductivity is calculated using the following expression(1):

$$
\lambda=\frac{Q \cdot h}{A \Delta T t}(1)
$$

Where: $\mathrm{Q}$ is the amount of conducted heat $(\mathrm{J})$; A is the area through Table I The properties of fabrics used in experiments

\begin{tabular}{|c|c|c|c|c|c|c|c|}
\hline Code & Knit & Composition (\%) and yarn count & $\begin{array}{l}\text { Course- } \\
\text { wale }(\mathrm{cm})\end{array}$ & $\begin{array}{l}\text { Thickness } \\
(\mathrm{mm})\end{array}$ & $\begin{array}{l}\text { Weight } \\
\left(\mathrm{gr} / \mathbf{m}^{2}\right)\end{array}$ & $\begin{array}{l}\text { Density } \\
\left(\mathrm{g} / \mathrm{cm}^{3}\right)\end{array}$ & $\begin{array}{l}\text { Porosity } \\
(\%)\end{array}$ \\
\hline Type1 & Single Jersey & 30/1 Ring Staple Fiber Polyester & $15-22$ & 0,52 & 160 & 0,30 & 96 \\
\hline Type 2 & Single Jersey & $\begin{array}{l}\text { 100/108 D Textured Polyester-\% } 91+20 \text { D } \\
\text { Elastan -\% } 9\end{array}$ & $16,5-26$ & 0,52 & 146 & 0,28 & 91,4 \\
\hline Type 3 & Single Jersey & $\begin{array}{l}\text { 100/96 D Textured Polyester-\% } 92.5+20 \text { D } \\
\text { Elastane- } \% 7.5\end{array}$ & $16-28$ & 0,58 & 152 & 0,26 & 91,2 \\
\hline Type 4 & Single Jersey & $\begin{array}{l}75 / 72 \text { Textured Moisture Management } \\
\text { Polyester- }(\% 85.9)+22 \text { dtex Elastan }(\% 14.1)\end{array}$ & $16-30$ & 0,432 & 113 & 0,26 & 92 \\
\hline Type 5 & Rainfall & 75/36 Textured Polyester & $13-37$ & 0,73 & 143 & 0,19 & 94,7 \\
\hline Type 6 & Rainfall & 75/96 Textured Polyester & $14-36$ & 0,568 & 121 & 0,21 & 92,9 \\
\hline Type 7 & Rainfall & 75/72 Moisture Management Polyester & $15-35$ & 0,6 & 113 & 0,18 & 93 \\
\hline Type 8 & Single Jersey & 150/48 Textured Polyester & $15-26$ & 0,58 & 171 & 0,29 & 90,2 \\
\hline Type 9 & Single Jersey & 150/288 Textured Polyester & $15-23$ & 0,438 & 146 & 0,33 & 93 \\
\hline Type 10 & Single Jersey & 75/72 X 2 Moisture Management Polyester & $15-26$ & 0,51 & 154 & 0,30 & 88,9 \\
\hline Type 11 & Mesh & $\begin{array}{l}\text { 220/360 D Textured Polyester- } \% 98+20 \text { D } \\
\text { Bright Polyester- } \% 2\end{array}$ & $13-17$ & 0,72 & 153 & 0,21 & 93 \\
\hline
\end{tabular}

Table 2 Microscope photos of three type of fibers used in the experiments

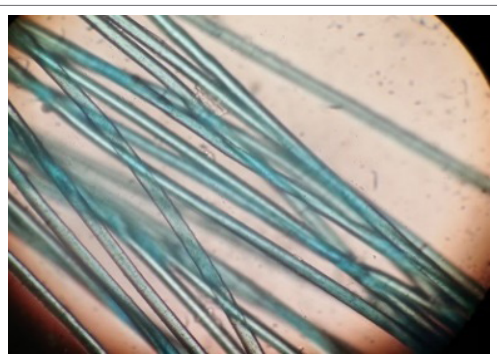

1. Staple Fiber Polyester

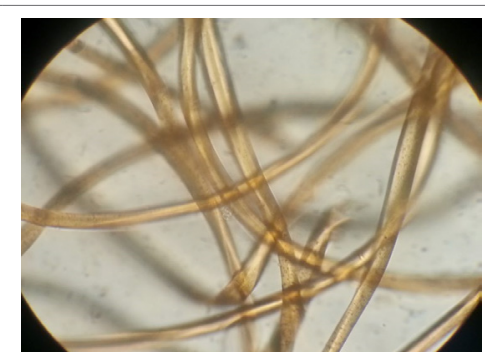

2. Textured Polyester which the heat is conducted $\left(\mathrm{m}^{2}\right) ; \mathrm{t}$ is the time of conductivity $(\mathrm{s}) ; \Delta T$ is the drop of temperature $(\mathrm{K})$; $\mathrm{h}$ is the fabric thickness $(\mathrm{m}) .{ }^{20}$

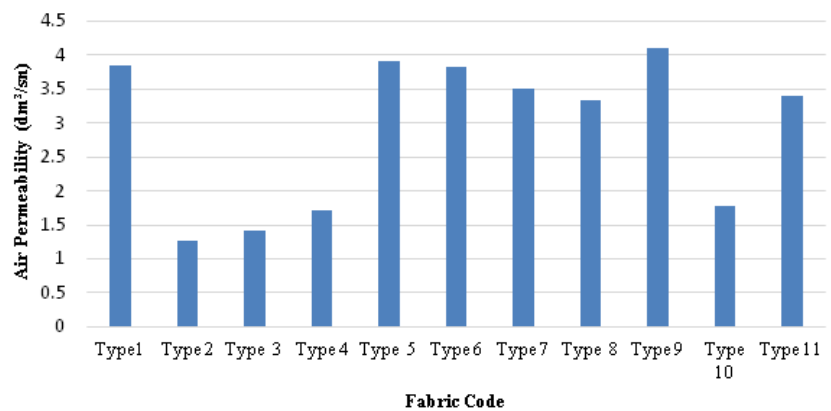

Figure I Air permeability values of fabrics used in the experiments.
The highest thermal conductivity value was seen in Type 2 and Type 3 textured polyester and elastan knitted single jersey fabrics. This is most probably due to elastan yarn composition. Comparison of mesh knitted Type 5, Type 6 and Type 7 rainfall knitted fabrics, the highest thermal conductivity value was seen in Type 5 the lowest filament number yarn knitted fabric. If we compare moisture managemet polyester knitted fabrics Type 4, Type 7 and Type 10; the highest thermal conductivity was shown in Type 10, the highest density fabric. This supports previous studies, the amount of fibre in the unit area increases and the amount of air layer decreases as

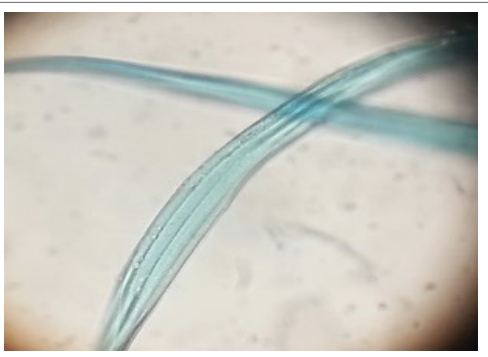

3. Moisture Management Polyester the weight increases. As is known, thermal conductivity values of fibres are higher than the thermal conductivity of entrapped air. ${ }^{21}$ Anova result of thermal conductivity values was given in Table 4 . The ANOVA results showed that the differences for the different types of fabric construction were significant in terms of the thermal conductivity.

\section{Thermal absorptivity}

A parameter to describe the warm-cool feeling of fabrics, namely the thermal absorptivity has been introduced. The thermal absorptivity 
is the parameter, characterizing the level of heat flow q, which passes between the human skin of infinite thermal capacity and temperature $\mathrm{t}_{1}$ and the contacting textile fabric. ${ }^{22}$

Table 3 ANOVA results of air permeability values

\begin{tabular}{llllll}
\hline & $\begin{array}{l}\text { Sum of } \\
\text { squares }\end{array}$ & df & $\begin{array}{l}\text { Mean } \\
\text { square }\end{array}$ & F & Sig. \\
\hline Between Groups & 96,480 & 10 & 9,648 & 696,945 &, 000 \\
Within Groups & 1,218 & 88 &, 014 & & \\
Total & 97,698 & 98 & & & \\
\hline
\end{tabular}

Table 4 ANOVA results of thermal conductivity values

\begin{tabular}{llllll}
\hline & $\begin{array}{l}\text { Sum of } \\
\text { squares }\end{array}$ & df & $\begin{array}{l}\text { Mean } \\
\text { square }\end{array}$ & F & Sig. \\
\hline Between Groups & 311,115 & 10 & 31,111 & 215,169 &, 000 \\
Within Groups & 3,181 & 22 &, 145 & & \\
Total & 314,296 & 32 & & & \\
\hline
\end{tabular}

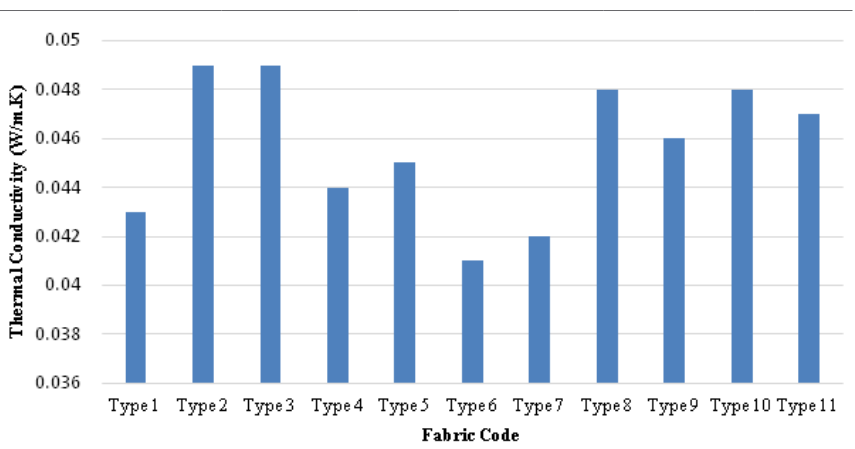

Figure 2 Thermal conductivity values of fabrics.

The thermal absorptivity values of fabrics were shown in Figure 3. Like thermal conductivity, the highest thermal absorptivity value was seen in Type 2, 100/108 D Textured Polyester-\% $91+20$ D Elastan - $\% 9$ textured polyester single jersey knitted fabric. The lowest thermal absorptivity values were seen in Type 5, Type 6 and Type 7 mesh knitted fabrics. Which means these fabrics feels warmer than the others in the first touch. When we compare same yarn count Type 8, Type 9 and Type 10 single jersey knitted fabrics, the highest filament number and density Type 9 was showed the highest thermal absorptivity value. The ANOVA results showed that the differences for the different types of fabric construction were significant in terms of the thermal absorptivity (Table 5).

Table 5 ANOVA results of thermal absorptivity values

\begin{tabular}{llllll}
\hline & $\begin{array}{l}\text { Sum of } \\
\text { squares }\end{array}$ & df & $\begin{array}{l}\text { Mean } \\
\text { square }\end{array}$ & F & Sig. \\
\hline Between Groups & $11,468,570$ & 10 & $1,146,857$ & 52,113 &, 000 \\
Within Groups & 484,160 & 22 & 22,007 & & \\
Total & $11,952,730$ & 32 & & & \\
\hline
\end{tabular}

\section{Thermal resistance}

Thermal resistance properties of fabrics were given in Figure 4. The highest thermal resistance value was seen in the highest thickness value textured polyester yarn knitted fabric Type 5 . When we compare mesh knitted fabrics Type 5, Type 6 and Type 7, the highest thickness and lowest filament number fabric Type 5 was showed the highest thermal resistance value. This is most probably due to the amount of still air in the spaces between the fibers is greater than the other two fabrics and the thermal resistance of air is relatively high compared to the textile fibers. Same results were seen Type 8, Type 9 and Type 10 fabrics. The highest thermal resistance value was seen in the lowest filament number fabric (Type 8). Additionally, lower filament number and higher thickness Type 3 was showed the higher thermal resistance value than Type 2. Lower filament number fabrics shows higher thermal resistance values in same yarn count of fabrics. The ANOVA results showed that the differences for the different types of fabric construction were significant in terms of the thermal resistance (Table 6).

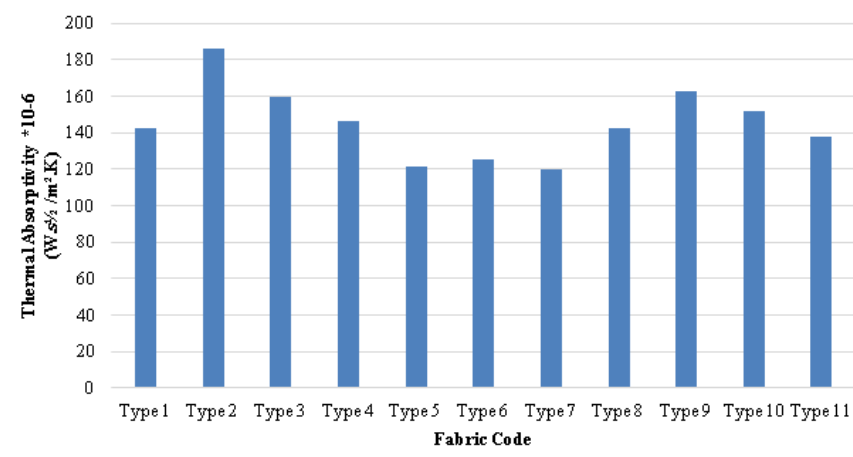

Figure 3 Thermal absorptivity values of fabrics.

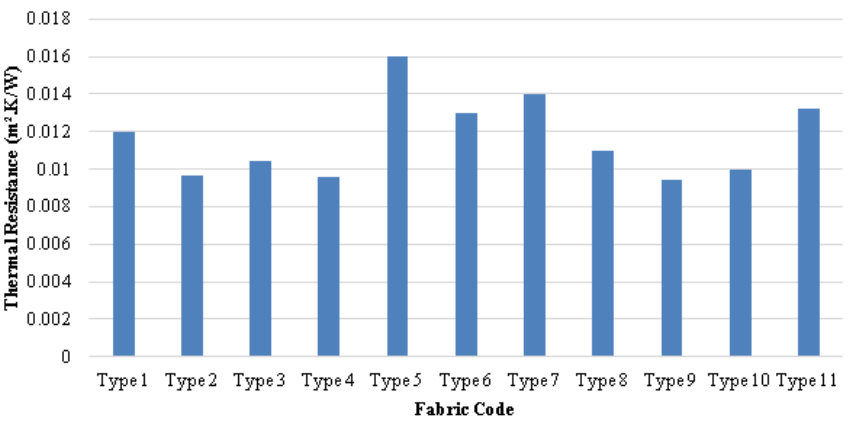

Figure 4 Thermal resistance values of fabrics.

Table 6 ANOVA results of thermal resistance values

\begin{tabular}{llllll}
\hline & $\begin{array}{l}\text { Sum of } \\
\text { squares }\end{array}$ & df & $\begin{array}{l}\text { Mean } \\
\text { square }\end{array}$ & F & Sig. \\
\hline Between Groups & 147,993 & 10 & 14,799 & $3,255,843$ &, 000 \\
Within Groups &, 100 & 22 &, 005 & & \\
Total & 148,093 & 32 & & & \\
\hline
\end{tabular}

The relationship between the thermal resistance and the thickness of fabrics is shown in Figure 5. The regression coeffcient was 0.69, indicating a relationship between the thermal resistance and the thickness of the fabric. The lowest thermal resistance value was seen in the lowest thickness value fabric Type 9 .

The effect of the fabric density on the thermal resistance of fabrics is shown in Figure 6. There was an inverse relationship between the fabric density and the thermal resistance. The regression coefficient is 0,76 . Thus, if the fabric density increases, the thermal resistance will decrease. The reason is that the lower the fabric density, the higher the amount of air trapped in the voids in the fabric. The higher the thermal resistance value of the air compared to the textile fibers, the lower the total heat transfer in the fabric and the higher the thermal resistance. 


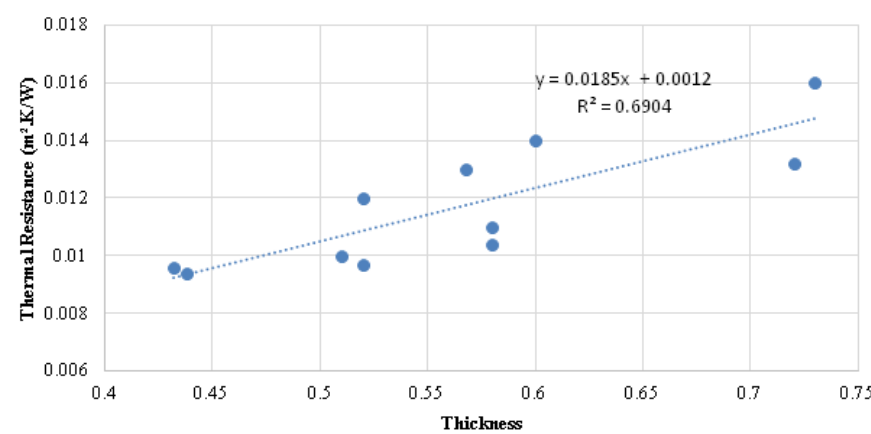

Figure $\mathbf{5}$ Thermal resistance and thickness relationship of fabrics.

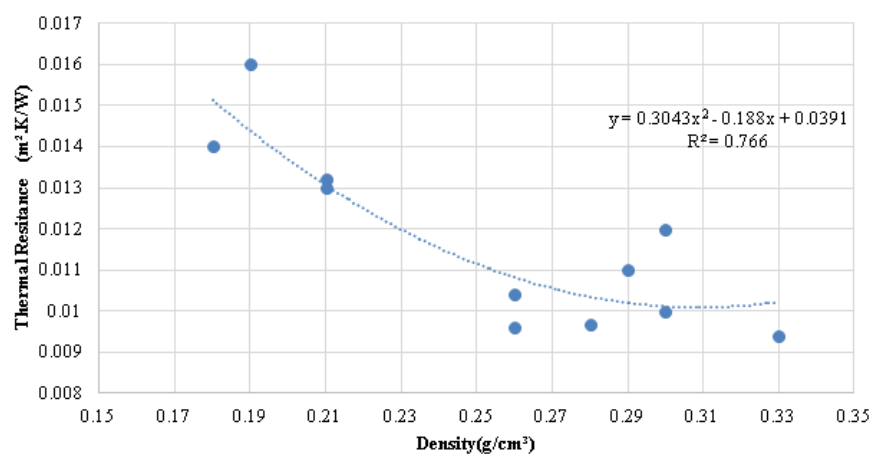

Figure $\mathbf{6}$ Thermal resistance and density relationship of fabrics.

\section{Moisture management properties of fabrics}

Moisture management properties of fabrics were given in Table 7. The top surface refers to the surface in contact with the skin. The bottom surface refers to the surface exposed to the atmosphere in the MMT test device.

\section{Top and bottom wetting times}

The wetting time is the start of the wetting of the upper and lower surfaces of the fabric after the start of the test. The wetting time values of fabrics used in the experiments were shown in Figure 7. Type 3 fabric was showed the highest top wetting time value. On the other hand, Type 2 fabric which is lower weight but higher filament number was showed lower wetting time values. The highest wetting time values were seen both top and bottom surfaces in Type $11-220 / 360 \mathrm{D}$ Textured Polyester-\% $98+20$ D Bright Polyester-\% 2 mesh knitted fabric which has also the highest yarn count and filament number. This means sweat solution slowly absorbed than the other fabrics. The lowest wetting time values were seen in top and bottom surfaces in Type 5, Type 6 and Type 7 rainfall knitted fabrics. Also, Type 4 moisture management fabric was showed quick wetting time values according to MMT grading scale.

\section{Absorption rate}

Absorption rate is defined as the average moisture absorbency ( $\% /$ sec) of the top and bottom surfaces of the fabric within the pumping time $(20 \mathrm{sec})$. The absorption rate of fabrics used in the experiments were shown in Figure 8. The highest top absorption rate was seen in Type 10 moisture management polyester knitted fabric. When we compare Type 8, Type 9 and Type 10 fabrics, moisture management polyester knitted fabric showed the highest absorption rate. On the other hand, Type 9 which has higher filament number than Type 8 was showed higher absorption rate values in top and bottom surfaces.
Type 5, Type 6 and Type 7 fabrics has showed similar absorption rate graphics and they were showed rapid absorption rates according to MMT scale. The highest bottom absorbency rate was seen in Type11 textured polyester mesh knitted fabric. The lowest top and bottom absorption rates was seen in Type 1 staple fiber polyester single jersey knitted fabric.

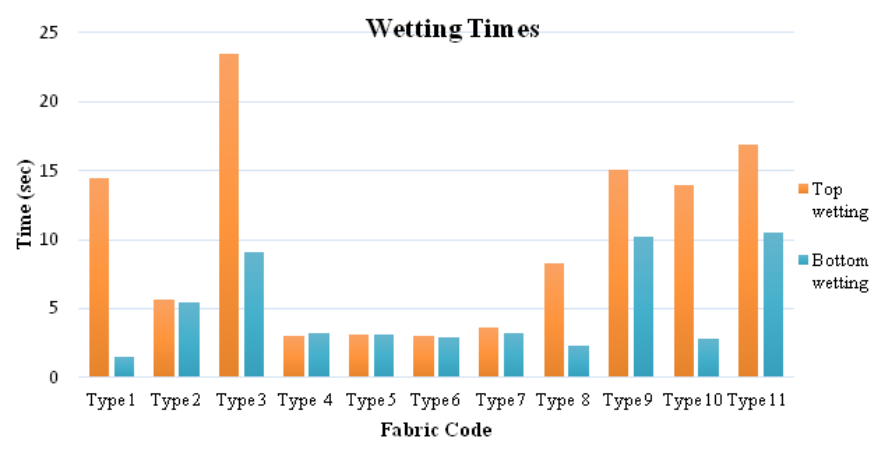

Figure 7 Wetting time values of fabrics.

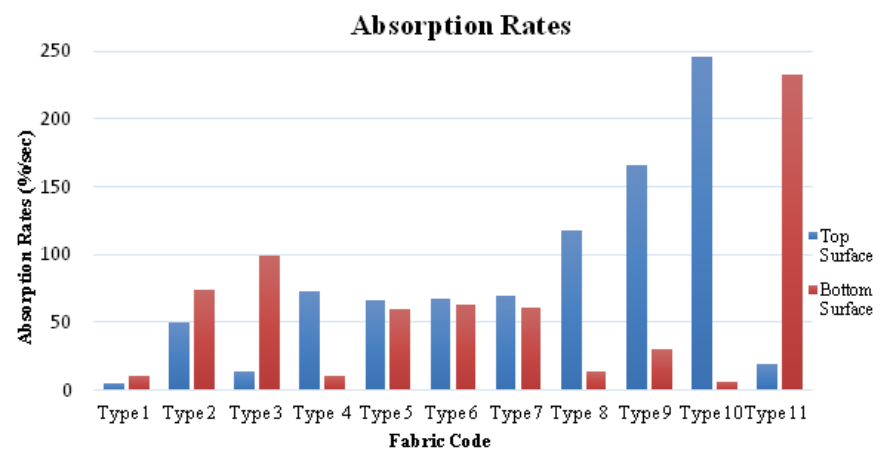

Figure 8 Absorption rate values of fabrics.

\section{Spreading speed}

Spreading speed are the speeds of the moisture spreading on the top and bottom fabric surfaces to reach the maximum wetted radius. ${ }^{23}$ The spreading speed of fabrics used in the experiments were given in Figure 9. If spreading speed value of fabric over the 4, according to MMT rating scale, sweat solution spreads very quickly to the fabric surface. Only Type 8 fabric was showed very quick spreading speed values both top and bottom surfaces. When we compare Type 8 , Type 9 and Type 10 same yarn count single jersey fabrics, Type 8 was showed very quick spreading speed than the others. Also wetting time values of this fabric lower than the other two fabric.

\section{OWTC and OMMC values of fabrics}

MMT grading scales were used to analize OMMC and OWTC values of fabrics (Table 8 ).

Accumulative one-way transport index (OWTC) is the difference of the accumulative moisture content between the two surfaces of the fabric. OWTC values of fabrics were given in Figure 10. The highest accumulative one way transport index values were seen in Type 1-30/1 Ring polyester and Type 10 moisture management polyester knitted single jersey fabrics. OWTC values of Type 5, Type 6 and Type 7 polyester rainfall knitted fabrics were found to be very poor according to the MMT evaluation scale.

Overall Moisture Management Capacity (OMMC) is an index to indicate the overall capability of the fabric to manage the transport 
of liquid moisture. Overall moisture management properties of fabrics are given in Figure 11. The overall moisture management properties of Type 5, Type 6 and Type 7 code rainfall knitted fabrics are poor. Although these fabrics shows good air permeability values, absorption rate and OWTC values are not good. OMMC values of
Type 3 and Type 11 fabrics were perfect according to MMT grading scale. When we compare moisture managemet polyester yarn knitted fabrics, except Type 7, were showed very good moisture management properties according to MMT grading scale.

Table 7 MMT test device measurements of fabrics

\begin{tabular}{|c|c|c|c|c|c|c|c|c|c|c|}
\hline $\begin{array}{l}\text { Fabric } \\
\text { Code }\end{array}$ & $\begin{array}{l}\text { WT (t) } \\
\text { (sec) }\end{array}$ & $\begin{array}{l}\text { WT (b) } \\
\text { (sec) }\end{array}$ & $\begin{array}{l}\text { TAR (\%/ } \\
\text { sec) }\end{array}$ & $\begin{array}{l}\text { BAR (\%/ } \\
\text { sec) }\end{array}$ & $\begin{array}{l}\text { MWR } \\
\text { (t) }(\mathrm{mm})\end{array}$ & $\begin{array}{l}\text { MWR (b) } \\
(\mathrm{mm})\end{array}$ & $\begin{array}{l}\mathrm{S} . \mathrm{S}(\mathrm{t})(\mathrm{mm} / \\
\mathrm{sec})\end{array}$ & $\begin{array}{l}\mathrm{S.S}(\mathbf{b}) \\
(\mathrm{mm} / \mathrm{sec})\end{array}$ & $\begin{array}{l}\text { OWTC } \\
(\%)\end{array}$ & OMМС \\
\hline Type 1 & 14,47 & 1,5 & 5,08 & 10,49 & 9 & 30 & 0,75 & 12,06 & 2461,6 & 0,75 \\
\hline Type 2 & 5,62 & 5,49 & 49,91 & 73,81 & 21,42 & 23,57 & 3,47 & 3,48 & 253,35 & 0,71 \\
\hline Type 3 & 23,45 & 9,06 & 14,1 & 99,09 & 9 & 19 & 0,3 & 5,13 & 1679,98 & 0,89 \\
\hline Type 4 & 2,98 & 3,24 & 72,94 & 10,61 & 20 & 16 & 4,08 & 3,19 & 1521,5 & 0,69 \\
\hline Type 5 & 3,13 & 3,16 & 66,76 & 59,7 & 20 & 20 & 3,82 & 3,72 & $-44,32$ & 0,37 \\
\hline Type 6 & 2,98 & 2,92 & 67,15 & 63,25 & 25 & 20 & 4,26 & 4,1 & $-27,83$ & 0,42 \\
\hline Type 7 & 3,61 & 3,26 & 69,85 & 60,76 & 20 & 20 & 3,34 & 3,63 & $-24,1$ & 0,38 \\
\hline Type 8 & 8,28 & 2,29 & 117,89 & 13,46 & 7,5 & 27,5 & 7,45 & 13,1 & 2242,2 & 0,73 \\
\hline Type 9 & 15,04 & 10,25 & 166,05 & 29,61 & 7,5 & 15 & 0,41 & 2,71 & 1750,1 & 0,7 \\
\hline Type 10 & 14,00 & 2,79 & 245,88 & 5,69 & 8 & 28 & 0,81 & 2,15 & 2328,8 & 0,75 \\
\hline Type 11 & 16,85 & 10,52 & 18,93 & 232,52 & 7,5 & 24,16 & 0,3 & 6,79 & 972,31 & 0,88 \\
\hline
\end{tabular}

Table 8 MMT grading scale for OWTC and OMMC values (MMT Test Device Manual)

\begin{tabular}{llllll}
\hline Index/Grade & $\mathbf{1}$ & $\mathbf{2}$ & $\mathbf{3}$ & $\mathbf{4}$ & $\mathbf{5}$ \\
\hline OWTC (\%) & $<-50$ Very Poor & $-50-99$ Poor & $100-199$ Good & $200-400$ Very Good & $>400$ Excellent \\
OMMC & $0-0.19$ Very Poor & $0.2-0.39$ Poor & $0.4-0.59$ Good & $0.6-0.8$ Very Good & $>0.8$ Excellent
\end{tabular}

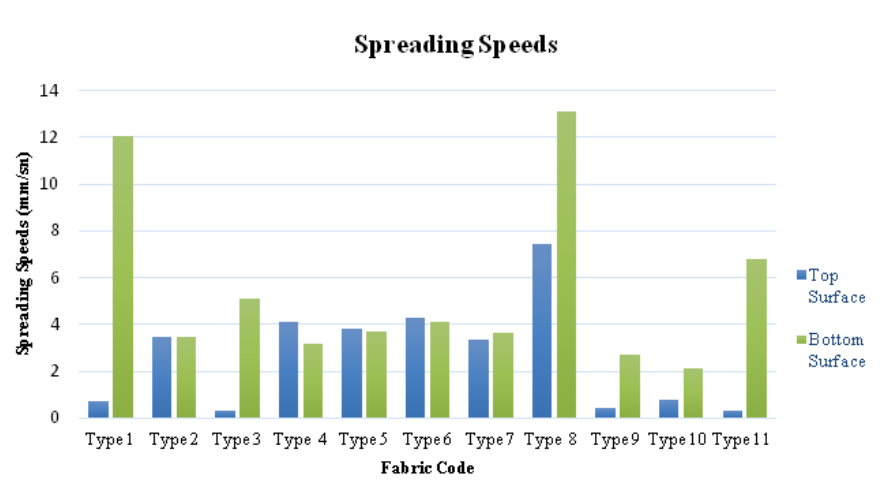

Figure 9 Spreading speed values of fabrics.

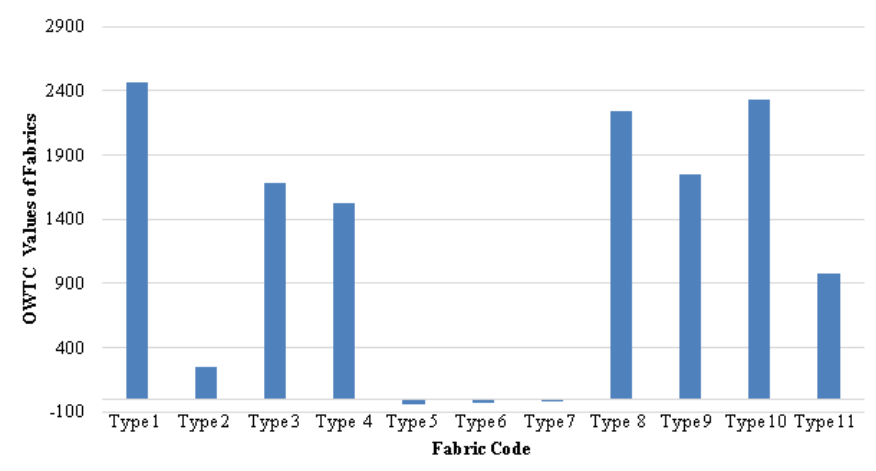

Figure 10 One way transport index values of fabrics.

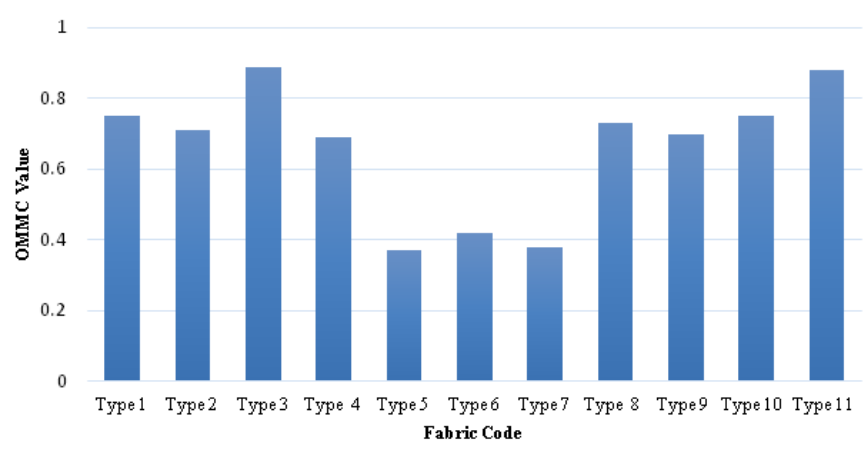

Figure II OMMC values of fabrics.

\section{Conclusion}

In this study, the thermophysiological comfort features of three different type of polyester knitted fabrics were investigated (staple, textured and moisture management polyester). Special type of polyester fabric were named as provide moisture management properties by producer. All the fabrics were compared in terms of their thermal resistance, thermal conductivity, thermal absorptivity, air permeability and moisture management. The results indicated that for same yarn count and knit structure, textured polyester yarn knitted fabrics more voluminous than moisture managemet polyester so they were showed higher air permeability values.

The highest thermal conductivity value was seen in Type 2 and Type 3 textured polyester and elastan knitted single jersey fabrics. 
This is most probably due to elastan yarn composition. The highest thermal resistance value was seen in the highest thickness value fabric Type 5. When we compare rainfall knitted fabrics Type 5, Type 6 and Type 7, the highest thickness and lowest filament number fabric Type 5 was showed highest thermal resistance value. This is most probably due to the amount of still air in the spaces between the fibers is greater than the other two fabrics and the thermal resistance of air is relatively high compared to the textile fibers. Like previous studies the relationship between the thermal resistance and the thickness (regression coefficient 0,69 ) and thermal resistance and density were observed (regression coefficient 0,76 ) between fabrics. ${ }^{16}$

According to MMT test results of fabrics, the highest wetting time value was seen Type 11 - textured polyester mesh knitted fabric. The highest top absorption rate was seen in Type 10 moisture management type of polyester. The highest bottom absorbency rate was seen in Type 11 textured polyester mesh fabric. Only Type 8 fabric was showed very quick spreading speed values both top and bottom surfaces. The highest accumulative one way transport index values were seen in Type 1-30/1 Ring polyester and Type 10 moisture management polyester knitted single jersey fabrics. OWTC values of Type 5, Type 6 and Type 7 polyester rainfall knitted fabrics were found to be very poor according to the MMT evaluation scale. OMMC values of Type 3 and Type 11 fabrics were perfect according to MMT grading scale.

As a result, textured polyester yarn knitted fabrics were showed the highest air permeability properties than moisture management polyester knitted fabrics in same yarn count and knit structure. On the other hand moisture management type of polyester knitted fabric (Type 10) has showed the highest top absorption and one way transport index value. Also moisture management polyester yarn knitted fabrics, except Type 7, were showed very good moisture management properties according to MMT grading scale.

\section{Funding}

This work was supported by Uludag University (project number BUAP (MH):2016/3).

\section{Acknowledgments}

None.

\section{Conflicts of interest}

Author declares there is no conflict of interest in publishing the article.

\section{References}

1. Slater K. Discussion paper the assessment of comfort. J Textile Institude. 1386;77(3):157-171.

2. Wong ASW, Li Y, Yeung PKW, et al. Neural network predictions of human psychological perceptions of clothing sensory comfort. Textile Research Journal. 2003;73(1):31-37.

3. Oğlakçığlu N \& Marmaralı A. Thermal comfort properties of some knitted structures. Fibres \& Text1les in Eastern Europe. 2007;15 (56):64-65.

4. Özçelik G, Çay A, Kirtay E. A study of the thermal properties of textured knitted fabrics. Flbres \& Textlles in Eastern Europe. 2007;15(1):55-58.

5. Fan J,Tsang HWK. Effect of clothing thermal properties on the thermal comfort sensation during active sports. Textile Research Journal. 2008;78(2):111-118.

6. Tyagi G K, Krishina G, Bhattacharya S, et al. Comfort aspects of finished polyester-cotton and polyester-viscose ring and MJS yarn fabrics. Indian Journal of Fibre and Textile Research. 2009;34(2):137143.

7. Majumdar A, Mukhopadhyay S, Yadav R. Thermal properties of knitted fabrics made from cotton and regenerated bamboo cellulosic fibres. International Journal of Thermal Sciences. 2010;49(10):2042-2048.

8. Sampath MB, Senthilkumar Mani S, Nalankilli G. Effect of filament fineness on comfort characteristics of moisture management finished polyester knitted fabrics. Journal of Industrial Textiles. 2011;41(2):160 173.

9. Cubric IS, Skenderi Z, Mihelic'-Bogdanic A, et al. Experimental study of thermal resistance of knitted fabrics. Experimental Thermal and Fluid Science. 2012;38:223-228.

10. Demiryürek O, Uysaltürk D. Thermal comfort properties of Viloft/ cotton and Viloft/polyester blended knitted fabrics. Textile Research Journal. 2013;83(16):1740-1753.

11. Wang F, Annaheim S, Morrissey M, et al. Real evaporative cooling efficiency of one-layer tight-fitting sportswear in a hot environment. Scand J Med Sci Sports. 2014;24(3):129-139.

12. Özgen B. Altaş S. The investigation of thermal comfort, moisture management and handle properties of knitted fabrics made of various fibres. Tekstil ve Konfeksiyon. 2014;24(3):272-278.

13. Lu Y, Wang F, Wan X, et al. Clothing resultant thermal insulation determined on a movable thermal manikin. Part II: effects of wind and body movement on local insulation. Int $J$ Biometeorol. 2015;59(10):1487-1498.

14. Ho C, Fan J, Newton E, et al. T-Shirt with propping effect for natural ventilation: design development and evaluation of its functionality by thermal manikin in standing and walking motions. Textile Science \& Engineering. 2015;5(5).

15. Atasağun $\mathrm{HG}$, Öner E, Okur A, et al. A comprehensive study on the general performance properties of Viloft-blended knitted fabrics. The Journal of The Textile Institute. 2015;106(5):523-535.

16. Özkan TE, Meriç B. Thermophysiological comfort properties of different knitted fabrics used in cycling clothes. Textile Research Journal. 2015;85(1):62-70.

17. Öner E, Okur A. Thermophysiological comfort properties of selected knitted fabrics and design of T-shirts. The Journal of The Textile Institute. 2015;106(12):1403-1414.

18. EN ISO 9237. Determination of the permeability of fabrics to air. 1995.

19. AATCC Test Method 195-2009. Liquid moisture management properties of textile fabrics.

20. Majumdar A, Mukhopadhyay S, Yadav R. Thermal properties of knitted fabrics made from cotton and regenerated bamboo cellulosic fibres. International Journal of Thermal Sciences. 2010;49(10):2042-2048.

21. Morton WE, Hearle JWS. Physical properties of textile fibres. The Textile Institute; 1993.

22. Hes L. Optimisation of shirt fabrics' composition from the point of view of their appearance and thermal comfort. International Journal of Clothing Science and Technology. 1999;11(2):105-119.

23. Hu J, Li Y, Yeung K, et al. Moisture management tester: a method to characterize fabric liquid moisture management properties. Textile Research Journal. 2005;75(1):57-62. 